\title{
SEPTIC SHOCK IN PATIENT WITH DISSEMINATED HISTOPLASMOSIS ASSOCIATED WITH AIDS: A CASE REPORT
}

Fabiano de Oliveira POSWAR(1), Jair Almeida CARNEIRO(1), Janice Mendes STUART(2), Jorge Patrick Oliveira FELICIANO(3) \& Daniella Cristina NASSAU(4)

\begin{abstract}
SUMMARY
Histoplasmosis is a systemic mycosis caused by Histoplasma capsulatum, which may present itself as a serious infection in immunocompromised individuals. We present a case of 31-year-old female with newly diagnosed HIV infection and history of fever, general and respiratory symptoms and diffuse hyperchromic papules through the body. She was admitted, with rapid progression to septic shock, and the presence of neutrophils filled with yeast-like organisms was detected on peripheral blood smear hematoscopia on the third day of hospitalization. The following is a brief review on the clinical picture and management of histoplasmosis.
\end{abstract}

KEYWORDS: Histoplasmosis; Mycoses; Acquired Immune Deficiency Syndrome.

\section{INTRODUCTION}

Histoplasmosis is a systemic mycosis caused by a dimorphic fungus called Histoplasma capsulatum. It is classically considered an endemic mycosis, although the fungus has an opportunistic behavior in patients with depressed cellular immunity.

Humans acquire the infection through the inhalation of conidia present in nature (bats found in caves and chicken stool). The clinical picture can vary from asymptomatic to severe disseminated infections. The diagnosis is based on the detection of the fungus in body fluids (sputum, blood, cerebrospinal fluid) or tissues (histopathology), the culture of biological and serological assays.

Treatment of the acute severe, chronic respiratory or localized forms can be done with oral azoles (itraconazole) and, in the disseminated form, amphotericin B is the drug of choice for initiating therapy (preferably lipid formulations).

Histoplasmosis is one of the most important systemic mycosis in the Americas, with widespread distribution in all regions of Brazil ${ }^{5,18}$. This paper aims to report a case of septic shock in a patient with disseminated histoplasmosis associated with acquired immunodeficiency syndrome (AIDS).

\section{CASE REPORT}

The patient was a 31-year-old female, born in Várzea da Palma-MG, admitted, by the emergency room, with productive cough with sputum, unmeasured fever, sore throat, fatigue, weight loss and hyporexia for a month. The patient reported the appearance of diffuse non-pruritic hyperpigmented papules throughout the body, and ulceration in the lower lip for 60 days.

On physical examination she presented a compromised general state of health, prostrated, a mild conjunctival pallor, hydrated, afebrile, mild edema of lower limbs and diffuse hypertrophic papules with sizes ranging from 0.5 to $1.0 \mathrm{~cm}$ through the body. The vital signs showed blood pressure (BP) of 90x60 mmHg, heart rate of $130 \mathrm{bpm}$, and respiratory rate of $30 \mathrm{rpm}$. Oroscopy showed mild enanthem of the oropharynx and purpuric patch on the lower lip.

On the first day of hospitalization, the patient remained asthenic and developed a productive cough, mucoid sputum and hemoptysis. Furthermore, a HIV serology was ordered, which retrieved a positive result. In the second day, she had diarrhea and fecal incontinence. Doses of clindamycin, ceftriaxone and sulfamethoxazole-trimethoprim were started. On the third day, the patient showed a decreased level of consciousness, hypoxemia and cardiopulmonary arrest (CPA) that was reversed with resuscitation maneuvers.

The patient also showed a Glasgow Coma Score (GCS) of 3, hemodynamic instability, inaudible BP and diminished vesicular murmurs bilaterally. An intubation was performed and mechanical ventilation, norepinephrine and dopamine were initiated. Patient status remained severe, with septic shock, unresponsive to resuscitation measures and high doses of amines. Blood gas analysis revealed severe metabolic acidosis and hypoxemia. Chest radiography showed diffuse bilateral 
POSWAR, F.O.; CARNEIRO, J.A.; STUART, J.M.; FELICIANO, J.P.O. \& NASSAU, D.C. - Septic shock in patient with disseminated histoplasmosis associated with AIDS: a case report. Rev. Inst. Med. Trop. Sao Paulo, 55(4): 283-6, 2013.

infiltrates, representative of the Acute Respiratory Distress Syndrome (ARDS). Peripheral blood smear was performed which revealed the presence of neutrophils filled with yeast-like organisms suggestive of Histoplasma capsulatum (Fig. 1). Amphotericin deoxycholate, vancomycin, piperacillin and tazobactam were then begun. In the fourth day, the patient presented another CRA in asystole and died.

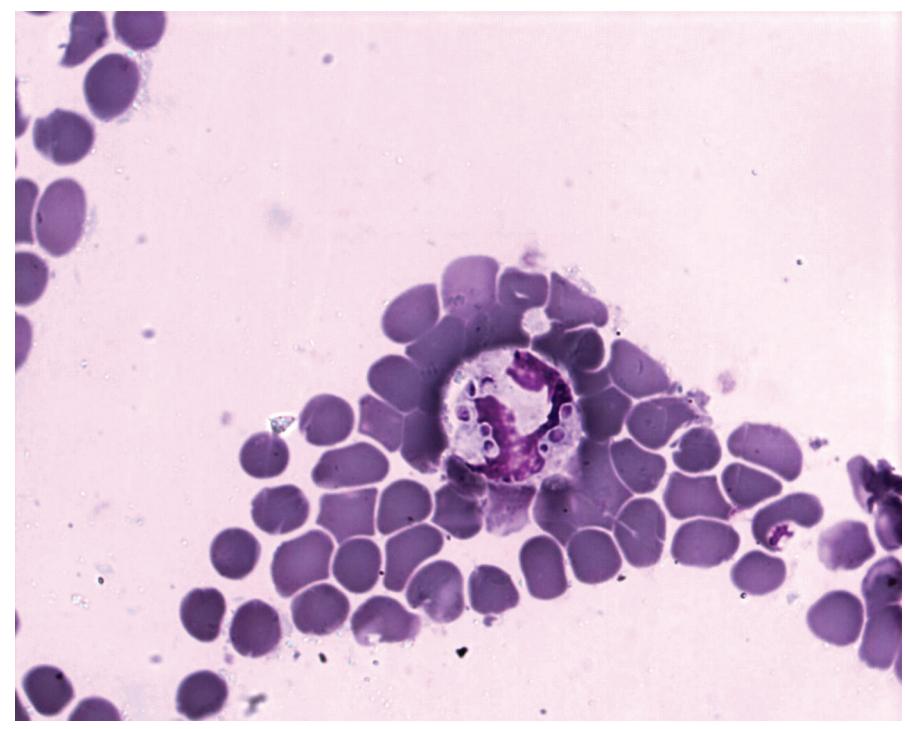

Fig. 1 - A neutrophil filled with yeast-like organisms suggestive of Histoplasma capsulatum.

\section{DISCUSSION}

Histoplasmosis is acquired through inhalation of conidia in nature. Most inhaled conidia arrive intact in the alveoli and stimulate a host's inflammatory response, consisting of mononuclear cells and macrophages, which are unable to destroy the microorganism. Histoplasma capsulatum multiplies inside the cells of the immune system and, through the lung, they enter into the perihilar and mediastinal lymph nodes and then into the systemic circulation, producing inflammatory foci in other organs such as the spleen and bone marrow.

After the second and third weeks of the onset of infection, it develops a cellular response of Th1 type, which will produce gammainterferon and other cytokines that activate macrophages, which have the capacity to lyse the intracellular yeast Histoplasma capsulatum. This type of immune response leads to healing of primary infection and in this state, people become very resistant to reinfection, but these are exceptional cases. Fungi can remain viable in scarred areas for several years.

Immunosuppression appears to be a major factor in triggering the reactivation of previous infection. Histoplasma capsulatum can be considered one of the most important opportunistic pathogens of the human body. Patients with lymphoma, heart, liver or renal transplant, patients using high doses of corticosteroids, and particularly AIDS patients may develop severe cases of disseminated histoplasmosis, resulting from the recrudescence of latent infections and, less frequently, new exposures to the microorganism in hyperendemic areas. As the patient of the current report was from a region where there are old houses and the tradition of breeding chickens, there was probably exposure to environments contaminated with the fungus, particularly chicken runs and roofs of abandoned houses. However, there are no studies of the actual occurrence of Histoplasmosis in this region that could characterize the area as hyperendemic.

The clinical form presented by individuals who become infected, depends upon the immune response, although, the inhaled inoculum size also has its importance. Patients with disseminated forms of the mycosis, like the patient of the current report, show a Th2-type immune response that produces IL4, IL5 and IL10, which inhibit the protective Th1 response. In this case, the granulomas are absents or poorly formed, there is a great proliferation of macrophages in tissues, the histoplasmin skin test is negative, the antibody titers are high and the course of disease is acute and severe ${ }^{5}$.

Primary infection with Histoplasma capsulatum, regardless of the presence of the symptoms may progress to the fungus spreading to the whole body, particularly to macrophage rich organs. Normally, as the specific anti-Histoplasma immunity develops, infection is controlled in the secondary metastatic foci and diagnosis may only be performed incidentally by biopsy showing the presence of yeast forms of the agent $t^{2,3,7,17}$.

Rarely, a small number of individuals with apparently normal immune systems or those with some form of immunosuppression may develop symptomatic disseminated histoplasmosis. Several conditions that evolve with cellular immune depression might influence the spread of the agent and, before the AIDS epidemic; patients with hematologic malignancies (leukemias, lymphomas), renal transplant patients, collagen diseases and sarcoidosis patients, corticosteroids users and those with primary cellular immunodeficiencies were the ones who most commonly developed systemic forms of the mycosis.

In AIDS patients, histoplasmosis is a severe, often fatal disease that occurs when the level of CD4 is below 200 cells $/ \mathrm{mm}^{3}$. In the patient of the current report, the level of CD4 and other relevant laboratorial data could not be investigated, since the disease progressed rapidly after the diagnosis. Accordingly, patients with AIDS often show a rapid progression of the disease with high fever, severe anorexia, malaise, nausea or vomiting, dyspnea, weight loss, generalized lymphadenopathy and hepatosplenomegaly. Disseminated skin lesions, as those of the case reported, are a common manifestation in these patients. Skin lesions can also be localized and involvement of the mucosa might occur. Bone marrow involvement is common and it is manifested by peripheral pancytopenia. Interestingly, pulmonary involvement in systemic histoplasmosis is rare, although, in severe cases of the disease, a miliary or interstitial pattern can be observed on chest radiographs.

Other laboratory abnormalities such as elevated liver enzymes (especially alkaline phosphatase and gamma-glutamyl transpeptidase), lactate dehydrogenase and ferritin, aside of hypoalbuminemia are commonly observed in these patients. Skin lesions, such as those reported in the patient, are very common in cases of histoplasmosis diagnosed in Latin America and may occur in up to half of diagnosed cases. They are polymorphic and are presented in the form of papules, nodules, ulcerations and located or ulcerated molluscoid lesions. Ulcerated mucosal lesions may occur in up to one third of cases ${ }^{2-4,7,15,17}$. 


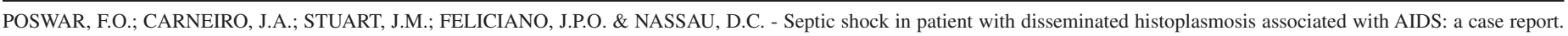
Rev. Inst. Med. Trop. Sao Paulo, 55(4): 283-6, 2013.

The patient of the current case report evolved with septic shock and lethal outcome. Indeed, with some patients the severe disseminated forms can exhibit a sepsis-like syndrome with hypotension, shock, disseminated intravascular coagulation and respiratory distress syndrome in adults with high mortality rates. Death is the spontaneous evolution of these clinical forms in most cases $^{14,16}$.

The diagnosis of histoplasmosis is based on finding the fungus on secretions and/or tissues and on particular serological reactions. In progressive disseminated histoplasmosis, the fungus can be seen on microscopic examination of smears of the peripheral blood, as occurred in this case report, as well as in bone marrow, skin or mucous lesion exudates, sputum and cerebrospinal fluid (CSF). The cultures of any of these materials may be positive. Blood cultures often isolate the causative agent, particularly in patients with AIDS. The histopathology is another way to make a diagnosis of histoplasmosis. Biopsies of skin or mucosa, lung, bone marrow, liver, lymph nodes and intestines show the presence of epithelioid granulomas, with a sarcoid aspect, where the microorganisms can be seen within phagocytic cells; special stains such as Gomori-Grocott and PAS are necessary for adequate visualization of the fungus ${ }^{11}$.

Several serological tests with different sensitivities and specificities are available for the diagnosis of histoplasmosis. Immunodiffusion and complement fixation, using histoplasmin as antigen show positive results in about $80 \%$ of patients, including those with self-limited acute infection. False-negatives may occur in immunocompromised patients with disseminated disease.

Complement fixation tests with titles of 1/32 or larger are suggestive of active infection. The immunodiffusion test is more specific, but less sensitive than the complement fixation. Immunoenzymatic techniques (ELISA) have also already standardized for the diagnosis of histoplasmosis and the previously accumulated clinical experience shows that these are more sensitive and specific than complement fixation ${ }^{11}$.

The antigen detection is the most useful method for the serological diagnosis of disseminated histoplasmosis in AIDS patients. Polysaccharide antigen of the fungus has been detected in the blood or in the urine in $85 \%$ and $95 \%$ of infected individuals, respectively. The test can also be applied in the cerebrospinal fluid and in respiratory secretions. Radioimmunoassay was the technique used for the fungus detection and is now commercially available. Skin tests using the histoplasmin are not recommended for the diagnosis, because a positive result does not distinguish past from current infection. Even a negative result does not rule out active disease. These tests are ideal for epidemiological studies in endemic areas of the mycosis ${ }^{16}$. Finally, detection methods based on polymerase chain reaction (PCR) have also been developed recently, although they lack standardization ${ }^{8}$. In the current report, as the fungus was found to be present in the peripheral blood smear, none of these methods were necessary. Nevertheless, in other cases, they can aid in the early diagnosis and treatment of the disease ${ }^{10}$.

In the primary therapy of disseminated histoplasmosis, particularly in patients with AIDS, amphotericin B is the drug of choice and must be administered in a total dose of $35 \mathrm{mg} / \mathrm{kg}$ (total dose for adults between 2.0 and $2.5 \mathrm{~g}$ ). About $75 \%-80 \%$ of patients show complete remission of clinical manifestations; but, when the drug is suspended, recurrences are common.
Long term maintenance therapy is required to maintain clinical remission in these patients; the amphotericin B at a dose of $1 \mathrm{mg} / \mathrm{kg}$, twice weekly, may be an alternative, although the dose of itraconazole $200 \mathrm{mg}$ $\mathrm{PO}$ once daily is also highly effective in this situation. Lipid formulations of amphotericin B at a dose of 3 to $5 \mathrm{mg} / \mathrm{kg} /$ day can also be employed and appear to be more effective than the deoxycholate formulation. After 1-2 weeks of use, and improvement of the patient, the sequential treatment with itraconazole must be performed $d^{13,15,16}$.

Despite the well-established treatment protocols, histoplasmosis remains a serious condition in a patient with AIDS, with mortality rates of up to $50 \%{ }^{4}$, which reinforces the need for new therapies and prevention strategies. Accordingly, new therapeutic targets, such as protein Hcp100 of the $H$. capsulatum, have been investigated and may result in the emergence of new drugs ${ }^{6}$. Prevention strategies to reduce exposure include avoiding caving or participation in demolitions in places known to be contaminated by $H$. capsulatum. In addition, in locations with an incidence of histoplasmosis higher than 10 cases per 100 patients-years, itraconazole $200 \mathrm{mg}$ daily may be used prophylactically to patients with CD4 counts less than $150 / \mathrm{mcL}^{13}$. Moreover, the large proportion of histoplasmosis patients who do not know to be infected with HIV or who are not making appropriate use of antiretroviral therapy of high efficiency reinforces the importance of screening programs of HIV infection and strategies for increasing the adherence ${ }^{4,5}$.

\section{RESUMO}

\section{Choque séptico em paciente com histoplasmose disseminada associada à AIDS: relato de caso}

A histoplasmose é micose sistêmica causada por Histoplasma capsulatum, a qual pode se apresentar de forma grave em indivíduos imunocomprometidos. Neste trabalho, apresenta-se o caso de paciente feminino, 31 anos, com diagnóstico recente de infecção por HIV e quadro de febre, sintomas gerais e respiratórios e pápulas hipercrômicas difusas pelo corpo. Foi internada, apresentando progressão rápida para choque séptico, sendo detectada a presença de leveduras inclusas em neutrófilos à hematoscopia no terceiro dia de internação. Apresenta-se uma revisão breve sobre a apresentação e o manejo clínico da histoplasmose.

\section{REFERENCES}

1. Baddley JW, Sankara IR, Rodriquez JM, Pappas PG, Many WJ. Histoplasmosis in HIV-infected patients in a southern regional medical center: poor prognosis in the era of highly active antiretroviral therapy. Diagn Microbiol Infect Dis. 2008;62:151-6.

2. Bonner JR, Alexander WJ, Dismukes WE, App W, Griffin FM, Little R, et al Disseminated histoplasmosis in patients with the acquired immune deficiency syndrome. Arch Intern Med. 1984;144:2178-81.

3. Borges AS, Ferreira MS, Silvestre MTA, Nishioka S de A, Rocha A. Histoplasmose em pacientes imunodeprimidos: estudo de 18 casos observados em Uberlândia, MG Rev Soc Bras Med Trop. 1997;30:119-24.

4. Brilhante RSN, Fechine MAB, Mesquita JRL, Cordeiro RA, Rocha MFG, Monteiro AJ, et al. Histoplasmosis in HIV-positive patients in Ceará, Brazil: clinical-laboratory aspects and in vitro antifungal susceptibility of Histoplasma capsulatum isolates. Trans R Soc Trop Med Hyg. 2012;106:484-8.

5. Ferreira MS, Borges AS. Histoplasmose. Rev Soc Bras Med Trop. 2009;42:192-8. 
POSWAR, F.O.; CARNEIRO, J.A.; STUART, J.M.; FELICIANO, J.P.O. \& NASSAU, D.C. - Septic shock in patient with disseminated histoplasmosis associated with AIDS: a case report. Rev. Inst. Med. Trop. Sao Paulo, 55(4): 283-6, 2013.

6. González-González AE, Taylor ML, Curiel-Quesada E. Aspectos relevantes del marcador molecular Hcp100 de Histoplasma capsulatum y su potencial uso terapéutico en la histoplasmosis. Rev Iberoam Micol. 2012;29:115-9.

7. Goodwin RA Jr, Shapiro JL, Thurman GH, Thurman SS, Des Prez RM. Disseminated histoplasmosis: clinical and pathologic correlations. Medicine (Baltimore). 1980;59:133.

8. Kauffman CA. Histoplasmosis. Clin Chest Med. 2009;30:217-25.

9. McKinsey DS, Wheat LJ, Cloud GA, Pierce M, Black JR, Bamberger DM, et al. Itraconazole prophylaxis for fungal infections in patients with advanced human immunodeficiency virus infection: randomized, placebo-controlled, double-blind study. National Institute of Allergy and Infectious Diseases. Mycoses Study Group. Clin Infect Dis. 1999;28:1049-56.

10. Vaidya OU, Vaidya AO, Patil HR, Huseth H. Fulminant sepsis due to disseminated histoplasmosis in renal transplantation: a diagnostic challenge. J Acute Med. 2012;2(2):55-7.

11. Wheat LJ. Diagnosis and management of histoplasmosis. Eur J Clin Microbiol Infect Dis. $1989 ; 8: 480-90$

12. Wheat LJ, Connolly-Stringfield PA, Baker RL, Curfman MF, Eads ME, Israel KS, et al. Disseminated histoplasmosis in the acquired immune deficiency syndrome: clinical findings, diagnosis and treatment, and review of the literature. Medicine (Baltimore). 1990;69:361-74.
13. Wheat LJ, Freifeld AG, Kleiman MB, Baddley JW, McKinsey DS, Loyd JE, et al. Clinical practice guidelines for the management of patients with histoplasmosis: 2007 update by the Infectious Diseases Society of America. Clin Infect Dis. 2007;45:80725 .

14. Wheat LJ, Kohler RB, Tewari RP. Diagnosis of disseminated histoplasmosis by detection of Histoplasma capsulatum antigen in serum and urine specimens. N Engl J Med. 1986;314:83-8.

15. Wheat J, Hafner R, Korzun AH, Limjoco MT, Spencer P, Larsen RA, et al. Itraconazole treatment of disseminated histoplasmosis in patients with the acquired immunodeficiency syndrome. AIDS Clinical Trial Group. Am J Med. 1995;98:336-42.

16. Wheat J, Hafner R, Wulfsohn M, Spencer P, Squires K, Powderly W, et al. Prevention of relapse of histoplasmosis with itraconazole in patients with the acquired immunodeficiency syndrome. Ann Intern Med. 1993;118:610-6.

17. Wheat LJ, Slama TG, Zeckel ML. Histoplasmosis in the acquired immune deficiency syndrome. Am J Med. 1985;78:203-10.

18. Zöllner MSA da C, Rezende KMP e C, Birman S, Elias CPF, Arisawa EÂL, Santos MABDV. Clinical and evolutionary characteristics of four patients with pulmonary histoplasmosis reported in the Paraíba Paulista Valley region. Rev Soc Bras Med Trop. 2010;43:599-601.

Received: 23 July 2012

Accepted: 3 December 2012 